\title{
The Use of Toll-like Receptor 4 Agonist to Reshape the Immune Signature in Ovarian Cancer
}

\author{
EVA VINDEVOGEL ${ }^{1}$, THAÏS BAERT ${ }^{1,2}$, ANAÏS VAN HOYLANDT ${ }^{1,2}$, \\ GODELIEVE VERBIST ${ }^{3}$, GREETJE VANDE VELDE ${ }^{4}$, ABHISHEK D. GARG ${ }^{5}$, \\ PATRICIA AGOSTINIS ${ }^{5}$, IGNACE VERGOTE ${ }^{1,2}$ and AN COOSEMANS ${ }^{1,2}$ \\ ${ }^{1}$ Laboratory of Tumor Immunology and Immunotherapy, Department of Oncology, \\ ImmunOvar Research Group, KU Leuven, Leuven, Belgium; \\ ${ }^{2}$ Department of Gynaecology and Obstetrics, Leuven Cancer Institute, \\ University Hospitals Leuven, Leuven, Belgium; \\ ${ }^{3}$ Department of Development and Regeneration, Organ Systems, KU Leuven, Leuven, Belgium; \\ ${ }^{4}$ Department of Imaging and Pathology, Biomedical MRI/MoSAIC, KU Leuven, Leuven, Belgium; \\ ${ }^{5}$ Laboratory for Cell Death Research and Therapy (CDRT), \\ Department of Cellular and Molecular Medicine, KU Leuven, Leuven, Belgium
}

\begin{abstract}
Background: Dendritic cell (DC) monoimmunotherapy has not been successful so far in ovarian cancer. The addition of a toll-like receptor (TLR) agonist has the potential to boost the innate immune system, in addition to the adoptive immune response initiated by DCs. Materials and Methods: ID8-fLuc C57BL/6 mice were injected with DCs loaded with hypericin-based photodynamic therapy-treated tumor lysate. A TLR4 agonist [lipopolysaccharide (LPS)] was administered by different schedules). After two and three DC vaccinations, immune analysis was performed. Results: There was no survival benefit from therapy with TLR4 agonist. Moreover, if LPS administrations started one week after tumor inoculation, the overall survival was even worse than that of untreated controls. Immune analyses revealed an intratumoral increase in natural killer cells and a decrease in regulatory T-cells, but an immunosuppressive signature in the ascites. Conclusion: Addition of LPS as an adjuvant to DC immunotherapy of ovarian cancer does not result in survival benefit.
\end{abstract}

This article is freely accessible online.

Correspondence to: An Coosemans, Laboratory of Tumor Immunology and Immunotherapy, KU Leuven, Herestraat 49, O\&N1, box 603, 3000 Leuven, Belgium. Tel: +32 16340809, email: an.coosemans@gmail.com

Key Words: Dendritic cell, ovarian cancer, toll-like receptor, TLR4, LPS, DC, mouse, immunotherapy.
Ovarian cancer is the second most lethal type of gynecological tumor with an incidence rate of $\sim 13$ per 100,000 women $(1,2)$. In general, ovarian cancer metastasizes throughout the abdomen before causing symptoms. Consequently, in $63 \%$ of patients this malignancy is detected at International Federation of Gynecology and Obstetrics (FIGO) stage III or IV, leading to a poor prognosis, with a median survival of 36-53 months for patients with stage III disease and 20 months for those with stage IV (3). Currently, $80 \%$ of patients die of their disease. Cytoreductive surgery in combination with platin-based (neo-)adjuvant chemotherapy remains the cornerstone of therapy (4). If the tumor relapses within 6 months after finishing the initial treatment with platin-derived chemotherapy, treatment options are restricted and prognosis is very poor. New treatment strategies are clearly necessary for ovarian cancer.

Avoiding immune destruction is an important hallmark of cancer (5). We and others have demonstrated that ovarian cancer has a strong immunosuppressive milieu (6). Immunosuppressive cells such as regulatory $\mathrm{T}$ cells $\left(\mathrm{T}_{\text {reg }}\right)$, myeloid-derived suppressor cells (MDSCs) and tumorassociated macrophages (TAMs) are attracted to the tumor microenvironment (TME) due to the secretion of chemokines, cytokines and other mediators $e . g$. transforming growth factor $\beta$ (TGF- $\beta$ ), galectin-1, vascular endothelial growth factor (VEGF), interleukin-6 (IL-6), IL-10, monocyte chemoattractant protein 1 (MCP-1), produced by tumor and immune cells present in and around the tumor $(7,8)$. These cells in turn also produce several factors that strengthen immunosuppression, leading to a cascade of immunosuppressive effects, all contributing to the escape of tumor cells from immune surveillance. 
The core message of immunotherapy is to increase the frequency of antigen-targeted cytotoxic T cells. Dendritic cell (DC) immunotherapy is capable of achieving this. Although several techniques can be used, the basis of the most commonly used method is that immature DCs are ex vivo loaded with a form of tumor-associated antigen, then maturated ex vivo and eventually administered to the patient (approximately 24 hours later). However, according to the latest Cochrane review, concerning antigen-specific active immunotherapy for ovarian cancer, including 3,051 women with epithelial ovarian cancer, this type of immunomonotherapy did not result in clinical benefit (9). For DC immunotherapy in particular, clinical studies in ovarian cancer are limited (10). The enormous immunosuppressive hurdle is most probably an important limiting factor against therapeutic success. Consequently, combination therapies will be necessary for effective immunotherapy in ovarian cancer $(11,12)$.

Toll-like receptors (TLR) are essential sensors of the innate immune system, and have the ability to recognize pathogenassociated and host-derived damage-associated molecular patterns (13-15). Pathogen-associated molecular patterns are well-conserved microbial products such as viral double-stranded RNA, lipopolysaccharide (LPS) derived from Gram-negative bacteria and the bacterial protein flagellin, which bind to TLR3, TLR4 and TLR5, respectively $(14,15)$. Host-derived damageassociated molecular patterns are endogenous ligands (e.g. heatshock proteins, calreticulin, ATP) released from stressed or dying tumor cells $(13,15-17)$. Upon recognition, TLRs are activated and trigger downstream pro-inflammatory signaling pathways [e.g. myeloid differentiation primary response 88 (Myd88) or TIR-domain-containing adapter-inducing interferon$\beta$ (TRIF)-dependent signaling pathway] in order to stimulate the transcription of factors [e.g. nuclear factor kappa-light-chainenhancer of activated B cells (NF-kB), interferon-regulatory factor (IRFs)] involved in inflammation and antitumor immunity $(15,18)$. Secretion of these mediators results in the recruitment and activation of immune effector cells. Eventually, TLR signaling results in the initiation of a tumor-eliminating inflammatory response characterized by cytolytic activity of certain natural killer (NK) cells (19). Additionally, TLR activation contributes to the initiation of an adaptive anti-tumor T-cell response. Intratumoral administration of the TLR4 agonist LPS in a rat glioma model led to tumor regression due to the generation of an antitumor response (20). Local administration of a TLR3 agonist also increased cluster of differentiation $8^{+}$ $\left(\mathrm{CD}^{+}\right)$T-cell activation in murine mesothelioma (21). Additionally, the research group of Vogel et al. reported that $\mathrm{CD}^{+}{ }^{+}$and $\mathrm{CD}^{+} \mathrm{T}$ cells proliferated in response to LPS (22). Scarlett et al. demonstrated, using an ovarian cancer mouse model, that the administration of a TLR3 agonist in combination with CD40 ligand reverted tumor-associated DCs to their immunostimulatory phenotype (23). In a phase II clinical trial of Brueseke et al., administration of a TLR8 agonist to patients with chemotherapy-resistant recurrent ovarian cancer resulted in the activation of an innate immune response and suppression of Treg (24). However, recent evidence showed that different tumor types, including ovarian cancer, also express functional TLR (25). In 2009, Zhou et al. reported strong expression of TLR2, TLR3, TLR4 and TLR5 on the surface epithelium of normal human ovaries, in human epithelial ovarian cancer and in human ovarian cancer cell lines based on immunohistochemical and functional analysis (26). In response to TLR activation, ovarian cancer cells can produce cell survival factors, pro-angiogenic factors and pro-inflammatory molecules in order to recruit immunosuppressive cells to the TME, stimulate tumor cell proliferation and suppress antitumor immunity $(18,26)$.

In this article, we explore the synergistic effect of DC immunotherapy and TLR4 administration in a mouse model of ovarian cancer using ID8 cells stably transduced with firefly luciferase (ID8-fLuc), allowing non-invasive tumor monitoring through bioluminescence imaging (BLI).

\section{Materials and Methods}

Mouse model of ovarian cancer. Six- to eight-week-old female C57BL/6 mice (Harlan Laboratories, Horst, the Netherlands) were inoculated intraperitoneally (i.p.) with $5 \times 10^{6}$ ID8-fLuc in $0.1 \mathrm{ml}$ sterile Dulbecco's phosphate-buffered saline (DPBS) (Lonza, Basel, Switzerland), as described earlier by our research group (27). All in vivo experiments were performed in accordance with the Federation for Laboratory Animal Science Associations guidelines and were approved by the Ethics Committee of the University Hospitals Leuven (P075/2014) (28). Mice were sacrificed according to the optimized euthanasia criteria described by Baert et al. (27).

DC-based immunotherapy. Ex vivo manufacturing of DCs was performed as described elsewhere by our research group (29). DC maturation was performed for 18 hours with $0.5 \mu \mathrm{g} / \mathrm{ml} \mathrm{LPS} \mathrm{(Sigma-}$ Aldrich). Immature DCs were loaded with tumor lysate treated with hypericin-photodynamic therapy (Hyp-PDT) as described elsewhere (17). DC-based vaccines $\left(1 \times 10^{6}\right.$ mature DCs per mouse) were administered subcutaneously to female C57BL/6 mice (Harlan Laboratories, Horst, the Netherlands), once every week for 3 weeks, starting 3 weeks after tumor inoculation. When Hyp-PDT-loaded DCs were administered in monotherapy, the therapy is referred to as DC mono, when they were administered in combination with a TLR4 agonist, the therapy is referred to as DC+LPS.

Administration of TLR4 agonist. LPS (40 $\mu \mathrm{g} / \mathrm{mouse})$ as TLR4 agonist was administered i.p. Administration schedules differed according to the different in vivo experiments (see Figure 1).

Bioluminescence imaging. Starting 1 week post ID8-fLuc inoculation, maximum luminescence after administration of DLuciferin (Promega, Madison, WI, USA) was measured as photons per second $(\mathrm{p} / \mathrm{s})$ through BLI on a weekly basis using IVIS Spectrum Preclinical In Vivo Imaging System (PerkinElmer, Waltham, MA, USA) at the Molecular Small Animal Imaging Centre (moSAIC) at the KU Leuven. 
A

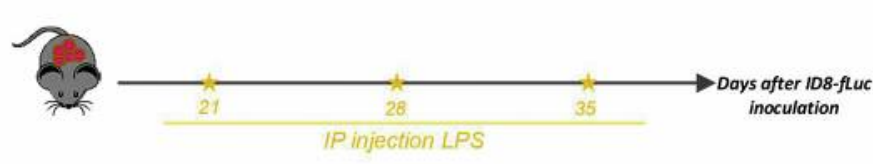

B ADMINISTRATION SCHEDULE IN VIVO 2

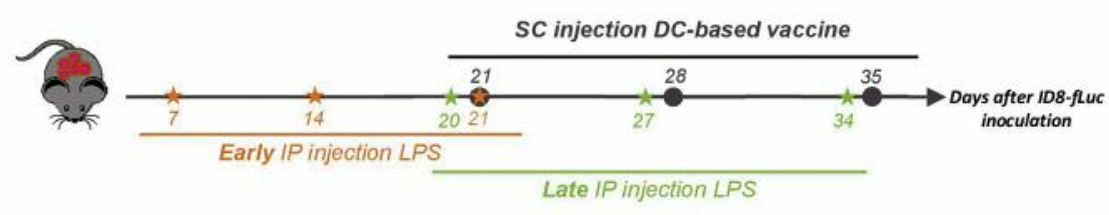

C ADMINISTRATION SCHEDULE IN VIVO 3

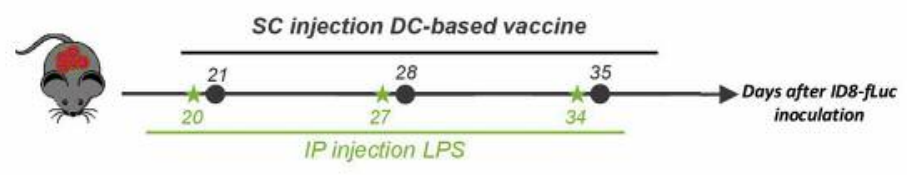

D ADMINISTRATION SCHEDULE IN VIVO 4

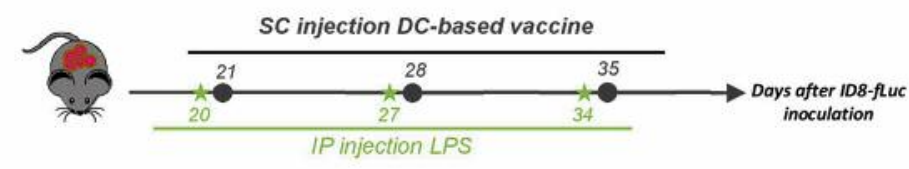

EXPERIMENTAL DESIGN IN VIVO 1

LPS mono

$n=3$
EXPERIMENTAL DESIGN IN VIVO 2

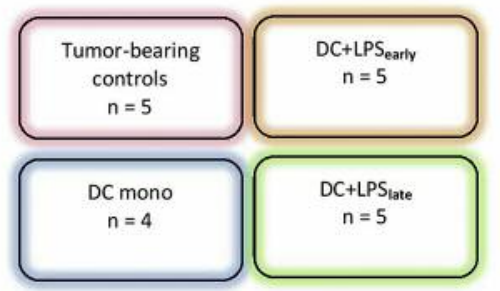

EXPERIMENTAL DESIGN IN VIVO 3

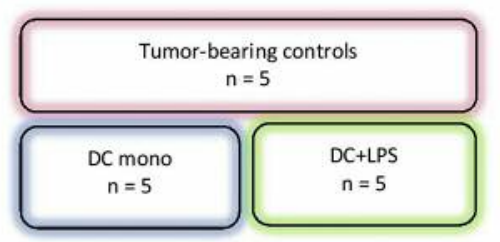

EXPERIMENTAL DESIGN IN VIVO 4

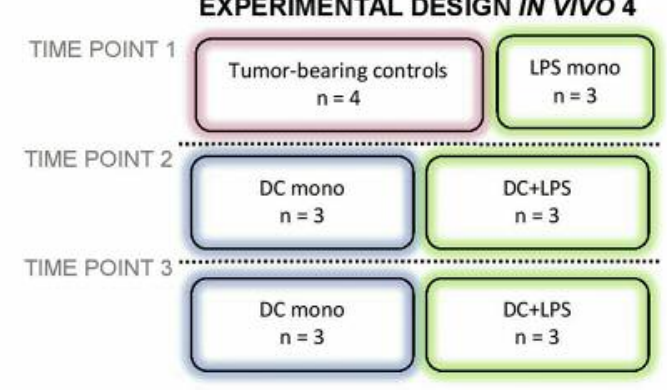

Figure 1. In vivo administration schedules and experimental design. Female C57BL/6 mice were injected i.p. with $5 \times 10^{6}$ ID8-fLuc cells (day 0). A: Small-scale toxicity experiment. Mice (n=3) received toll-like receptor 4 (TLR4) agonist lipopolysaccharide (LPS) i.p. 21, 28 and 35 days after ID8fLuc inoculation. B: Dendritic cell (DC) immunotherapy in combination with LPS to explore a potential synergistic effect in terms of survival. DCbased vaccination was administered subcutaneously to the corresponding groups for 3 consecutive weeks starting on day 21 after ID8-fLuc inoculation. LPS was injected i.p. in accordance with a fixed schedule: early administration occurred on days 7, 14 and 21 after ID8-fLuc inoculation; late administration occurred on day 20, 27 and 34 after ID8-fLuc inoculation. C: DC immunotherapy in combination with LPS administered one day prior to each DC-based vaccination, i.e. on days 20, 27 and 34 after ID8-fLuc inoculation, in order to reassess the effect of the combination immunotherapy by monitoring survival, weight and tumor load. D: Mice were treated as described in $C$ then sacrificed at three different time points for immune monitoring: before, and after two and three vaccinations, corresponding to days 21, 35 and 42 after ID8-fLuc inoculation.

Immunomonitoring. The immune status of mice was evaluated at three different time points: before, and after two and after three DCbased vaccinations (Figure 1D).

Cells from the spleen, ascites and draining lymph nodes were assessed for the expression of CD45 [Alexa Fluor 700 (AF700) conjugated clone 30-F11; ebioscience, Vienna, Austria], major histocompatilibity complex-II molecule (MHCII/IA-IE) [peridinin chlorophyll-cyanine 5.5 (PerCP-Cy 5.5) conjugated clone M5/114.15.2; BD Bioscience, Erembodegem, Belgium], CD4 (PerCP-Cy 5.5 conjugated clone RM4-5; ebioscience), forkhead box P3 (FOXP3) [phycoerythrin (PE) conjugated clone JFK-16s; eBioscience], CD11b [brilliant violet 421 (BV421) conjugated clone M1/70; BD Bioscience], granulocytic marker (Ly-6G/Ly-6C (GR1) [fluorescein isothiocyanate (FITC) conjugated clone RB6-8C5; BD Bioscience], CD3 (FITC conjugated clone 145-2c11; BD Bioscience), CD8a (BV421 clone 536.7 BD Bioscience) and CD335 (NKp46) [allophycocyanin (APC) conjugated clone 29A1.4; Biolegend, San Diego, CA, USA] by fluorescence-activated cell sorting (FACS) analysis. 
ELISA was performed to determine the level of VEGF in samples of ascites supernatants, as described above. Serum and ascites of these mice was also assayed for the presence of IL-1 $\beta$, IL-6, IL_10, IL-12p70, IL-17A, tumor necrosis factor- $\alpha$ (TNF- $\alpha$ ), interferon- $\gamma$ (INF $\gamma$ ) and MCP-1 using CBA, as described above.

Tumor tissue (peritoneum, diaphragm and omentum) collected at the three different time points was stained for the presence of TLR4, FOXP3 and natural cytotoxicity triggering receptor 1 (NRC1). In brief, paraffin-embedded tissue slices were deparaffinized and permeabilized in ethanol. Endogenous peroxidase activity was blocked by $0.5 \% \mathrm{H}_{2} \mathrm{O}_{2}$ in methanol. After washing with DPBS, heat-mediated antigen retrieval was carried out at $95^{\circ} \mathrm{C}$ in a citrate buffer at $\mathrm{pH} 6$ for 1 hour for FOXP3 and 2 hours for NCR1, or in a Tris-HCl buffer at pH 9 supplemented with $1 \mathrm{mM}$ EDTA for TLR4. After washing with DPBS, non-specific binding was blocked and sections were incubated overnight at $4^{\circ} \mathrm{C}$ with a primary antibody: mouse anti-TLR4 (1:100 dilution; Abcam, Cambridge, UK), rat antimouse FOXP3 (1:100 dilution; eBioscience) and rabbit anti-NCR1 (1:100; Bioss Antibodies, MA, USA). After washing, sections stained for TLR4 and NCR1 were incubated with an anti-mouse (for TLR4) or anti-rabbit (for NCR1) horseradish peroxidase-labelled polymer as secondary antibody (EnVision+ System; Dako Belgium, Heverlee, Belgium). After another blocking step, sections stained for FOXP3 were incubated with a biotinylated goat anti-rat secondary antibody (1:400 dilution; Abcam) and normal mouse serum (1:25 dilution) as secondary antibody, followed by an incubation with peroxidase-conjugated streptavidin (Dako Belgium). Staining was performed using 3,3'-diaminobenzidine (DAB). Sections were counterstained with Mayer's hematoxylin solution, dehydrated with ethanol and mounted in DePex medium.

Phenotypic analysis of (im)mature DC using fluorescence-activated cell sorting (FACS). Quality control of immature and mature DCs was performed as described before (29). Acquisition was performed using Cellquest software on a LSR Fortessa FACSort cytometer (BD bioscience). Analysis was performed using FlowJo Single Cell Analysis software (TreeStar, Inc., Ashland, OR, USA).

Functional TLR4-screening. ID8-fLuc cells were cultured at a density of $5 \times 10^{5}$ cells $/ \mathrm{ml}$ medium with or without LPS $(10 \mu \mathrm{g} / \mathrm{ml}$; Sigma-Aldrich, Diegem, Belgium). After 24 hours of incubation, cell supernatants were collected and analyzed for the presence of IL-1 $\beta$, IL-6, IL-10, IL-12p70, IL-17A, TNF- $\alpha$, IFN $\gamma$ and MCP-1 using a cytometric bead array (CBA) (BD bioscience, Erembodegem, Belgium) according to the company's protocol. LSR Fortessa (BD bioscience) was used to acquire the samples. Cytokine and chemokine concentrations $(\mathrm{pg} / \mathrm{ml})$ were quantified and analyzed for each sample using FCAP Array ${ }^{\mathrm{TM}}$ Software 3.0 (BD bioscience). Enzyme-linked immunosorbent assay (ELISA) was performed to determine the level of VEGF, using the mouse DuoSet ${ }^{\circledR}$ ELISA Development Systems (R\&D Systems, Minneapolis, MN, USA) according to the manufacturer's instructions. The optical density (OD) was determined using a Multiskan RC Microplate Reader (LabSystems, Helsinki, Finland). Reading was performed at 450 nm. Data analysis was carried out using the dedicated LabSystems Genesis $^{\mathrm{TM}}$ Software 3.03 (LABSYSTEMS, Helsinki, Finland).

Proliferation assay. ID8-fLuc cells were cultured in 96-well plates at a density of $1 \times 10^{5}, 5 \times 10^{4}$ and $1 \times 10^{4}$ cells per well. Cells were cultured in the presence or absence of LPS $(10 \mu \mathrm{g} / \mathrm{ml})$ during 24 and
48 h. Next, $100 \mu$ l of 3-(4,5-dimethyl-2-thiazolyl)-2,5-diphenyl-2Htetrazolium bromide (MTT; $0.5 \mathrm{mg} / \mathrm{ml}$ culture medium; SigmaAldrich, Diegem, Belgium) was added. After incubation, MTT solution was removed and dimethyl sulfoxide (DMSO) was added. The OD, used as a measure of cell proliferation, was determined using a Multiskan RC Microplate Reader (LABSYSTEMS) set to 570 $\mathrm{nm}$. The reference wavelength was set to $620 \mathrm{~nm}$. Values of blanks were used for compensation. ID8-fLuc cells cultured in plain medium and $90 \%$ DMSO were used as control conditions. Data analysis was carried out using the LabSystems Genesis ${ }^{\mathrm{TM}}$ Software 3.03.

Statistical analysis. Data analysis was performed using the statistical software package Prism 5.02 (GraphPad Software, Inc., San Diego, CA, USA). Experimental results with $p<0.05$ were considered to be statistically significant. Shapiro-Wilk test was performed to evaluate normality. Kaplan-Meier plots were used to evaluate the overall survival of mice. To compare the survival curves, log-rank testing was performed. Wherever applicable, a Mann-Whitney, KruskalWallis or $t$-test was performed.

\section{Results}

Despite TLR4 positivity of ID8-fLuc cells, their behavior is not altered by the addition of a TLR4 agonist LPS. Immunohistochemistry showed a moderate and diffuse expression of TLR4 in metastatic tumor implants in mice with ovarian cancer (Figure 2A). In order to evaluate if the presence of LPS in the tumor microenvironment might have a direct effect on proliferation of the ID8-fLuc cells, we performed an in vitro MTT assay, which did not show a significant change in cell proliferation in the presence or absence of LPS (Figure 3). Similarly, there was no significant change in the production of IL-6, IL-10, MCP-1 and VEGF upon the addition or omission of LPS in the in vitro system (Figure 4). In the same experiment, we measured the concentrations of IL-1 $\beta$, IL-12p70, IL-17A, TNF- $\alpha$ and IFN- $\gamma$ in ID8-fLuc supernatants, which were extremely low or undetectable, therefore, data are not shown.

Feasibility and toxicity of intraperitoneal administration of TLR4 agonists. A small-scale in vivo toxicity experiment was conducted to assess the safety of i.p. administration of LPS starting 3 weeks after tumor inoculation (Figure 1A). ID8fLuc C57BL/6 mice received LPS (40 $\mu \mathrm{g} / \mathrm{mouse}$ ) once a week for 3 successive weeks. Potential short-term and longterm adverse effects were evaluated as described in literature (27). Despite one sudden death, due to a technical inaccuracy (excluded value), this experiment revealed that LPS was well-tolerated. Of note, administration of LPS did not alter the immunohistochemical expression profile of TLR4 in ID8-fLuc cells (Figure 2B).

Addition of a TLR4 agonist to DC immunotherapy has a time-dependent effect on survival of mice with ovarian cancer. The experimental set up is displayed in Figure 1B. 

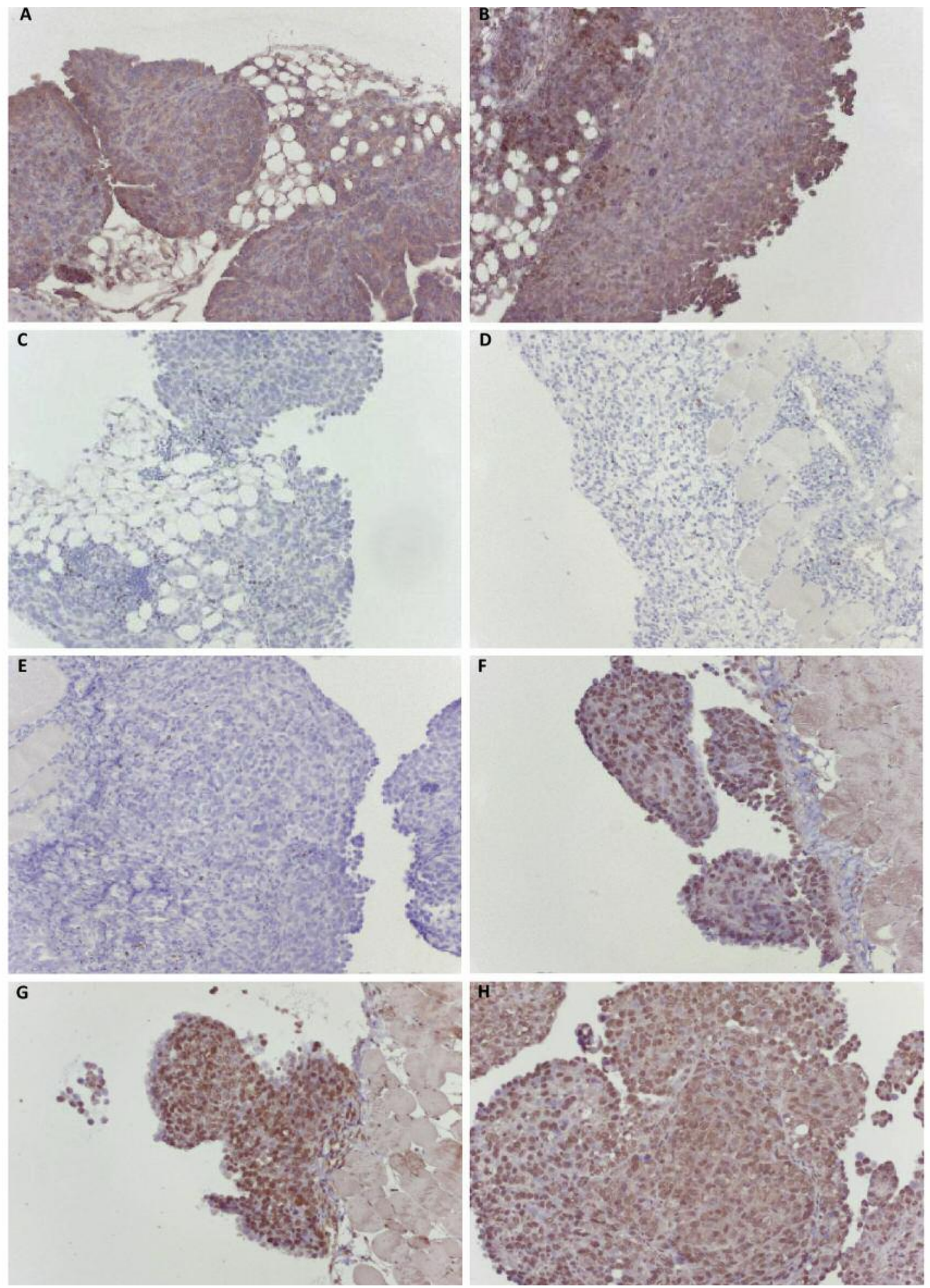

Figure 2. Immunohistochemical staining (magnification at $\times 64)$ of tumor tissue obtained from mice treated with lipopolysaccharide (LPS) monotherapy, dendritic cell (DC) immunotherapy in combination with LPS or untreated controls. Cytoplasmatic toll-like recptor 4 (TLR4) staining (brown) in omentum of untreated control mice (A) and mice treated with LPS monotherapy (B). Nuclear forkhead box P3 (FOXP3) staining (brown) in omentum of tumor-bearing control mice $(C)$ and in peritoneum of DC+LPS treated mice after two $(D)$ and after three $(E)$ DC vaccinations. Nuclear natural cytotoxicity triggering receptor 1 (NCR1) staining (brown) in peritoneum of tumor-bearing control mice $(F)$ and of DC+LPStreated mice after two $(G)$ and after three $(H) D C$ vaccinations. 
In the case of early LPS administration, mice had a significantly $(p=0.0218)$ shorter overall survival (median $=88$ days) than mice, which only received Hyp-PDT-loaded DC (median=119 days) (Figure 5). These mice also developed ascites earlier compared to the DC mono-treated mice. When LPS was administered from one day prior to each DC immunotherapy (DC+LPS late) median survival was comparable to that of the DC mono-treated group.

Administration of a TLR4-agonist one day prior to each $D C$ immunotherapy does not result in reduction of tumor growth or survival benefit. In an attempt to explore the potential of DC+LPS ${ }_{\text {late }}$, the experiment was repeated. We evaluated tumor growth through BLI. In all mice, tumor growth was detectable within 1 week after tumor challenge (Figure 6B). BLI scanning was performed until 6 weeks after tumor inoculation and was stopped due to the development of ascites (Figure 6C) (27). The combination of DC immunotherapy with LPS administration was unable to reduce tumor growth compared to untreated mice. Furthermore, it was clear that the addition of LPS from one day prior to DC immunotherapy did not induce a survival benefit (Figure 6A). Mice treated with the combination therapy had a significantly shorter median survival compared to mice of the DC mono-treated group $(p=0.0027)$ and even to the tumor-bearing controls $(p=0.0047)$. Moreover, all mice treated with the combination therapy manifested signs of disease before the mice of the other groups did.

Combination immunotherapy leads to positive immune changes in the tumor. After two vaccinations, the proportion of intratumoral FOXP3 ${ }^{+}$T-cells had decreased in mice treated with the combination immunotherapy compared to tumor-bearing controls (Figure $2 \mathrm{C}$ and $\mathrm{D}$ ). This effect was less clear after three vaccinations (Figure $2 \mathrm{C}$ and $2 \mathrm{E}$ ). Immunohisto-chemistry revealed a high level of $\mathrm{NCR} 1^{+} \mathrm{NK}$ cells in tumor tissue obtained from tumor-bearing controls (Figure 2F). In comparison with the tumor-bearing controls, tumor samples obtained from mice of the combination immunotherapy group exhibited a clear increase in the proportion of NK cells after two and three vaccinations (Figure 2F-H).

Immunosuppressive cells and cytokines present in ascites overwhelm the antitumor immune response. First we performed FACS analysis to investigate the immune cells present in ascites after combination treatment. The relative number of $\mathrm{CD}^{+}{ }^{+} \mathrm{CD} 4^{+}$and $\mathrm{CD} 3^{+} \mathrm{CD} 8^{+} \mathrm{T}$-lymphocytes in ascites decreased after two and three vaccinations with combination immunotherapy (Figure $7 \mathrm{~A}$ and B). Simultaneously, the relative proportion of $\mathrm{CD} 5^{+} \mathrm{CD} 4{ }^{+} \mathrm{FOXP}^{+}{ }^{+} \mathrm{T}_{\text {reg }}$ was increased compared to
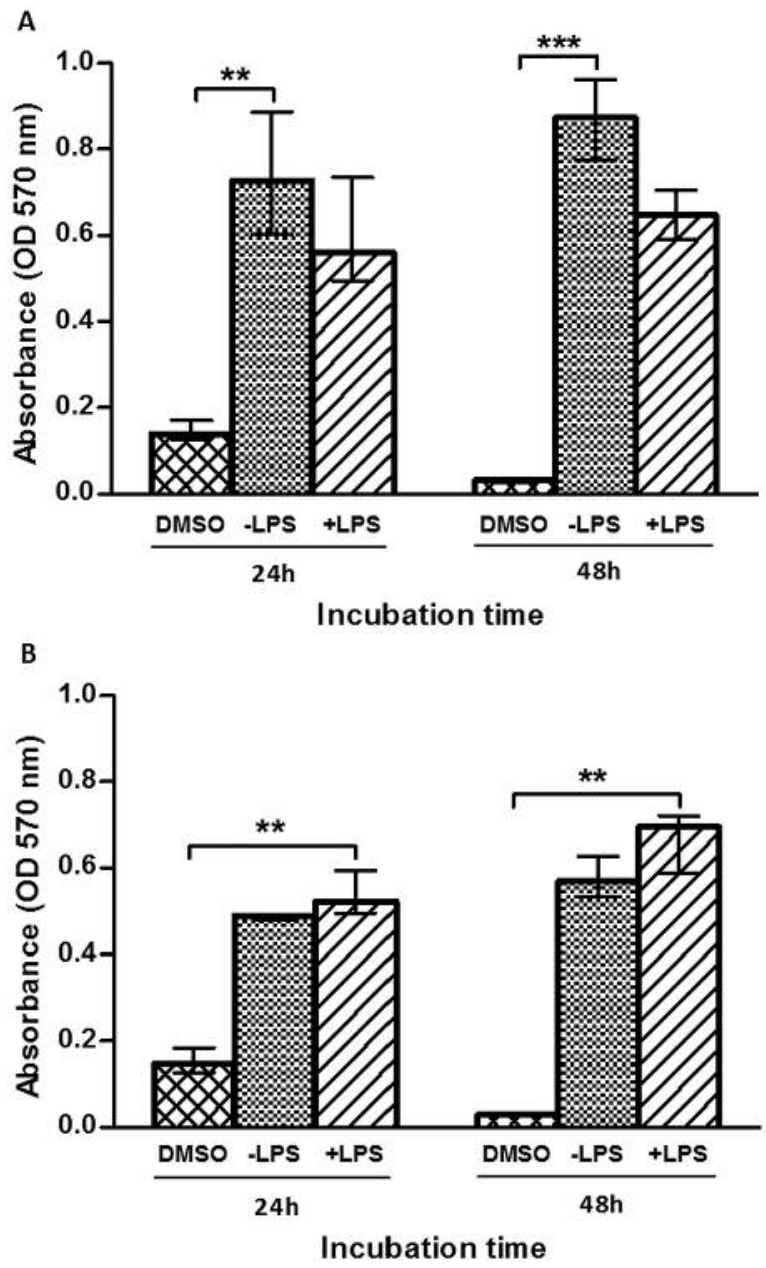

C

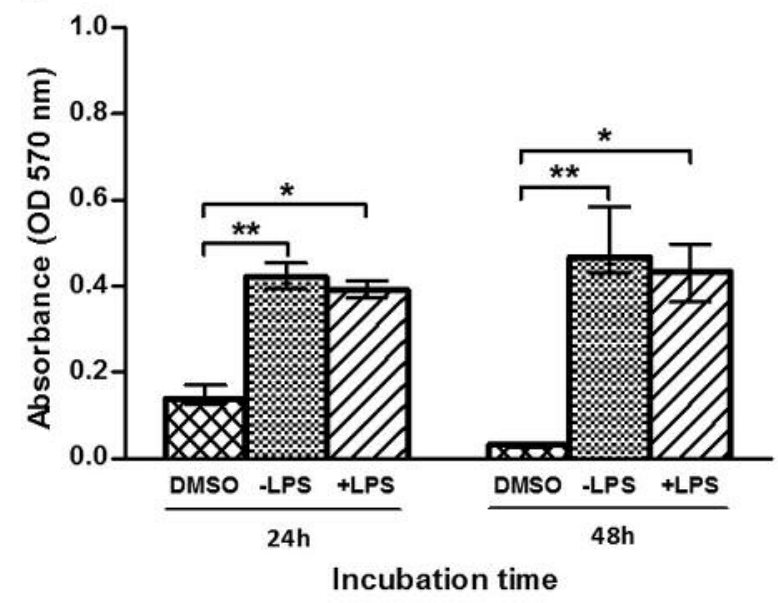

Figure 3. Proliferation assay. A total of $1 \times 10^{5}$ (A), $5 \times 10^{4}$ (B) and $1 \times 10^{4}(C)$ ID8-fLuc cells were cultured in medium consisting of $90 \%$ dimethyl sulfoxide (control condition), in medium supplemented with lipopolysaccharide (LPS) $(10 \mu \mathrm{g} / \mathrm{ml})$ or in plain medium (LPS negative control). After 24 and $48 \mathrm{~h}$, metabolic activity was assessed using the 3-(4,5-dimethylthiazol-2-yl)-2,5-diphenyltetrazolium bromide (MTT) proliferation assay. Statistically significant difference by Kruskal-Wallis test at $* p<0.05, * * p<0.01, * * * p<0.001 .0 D$, Optical density. 
A

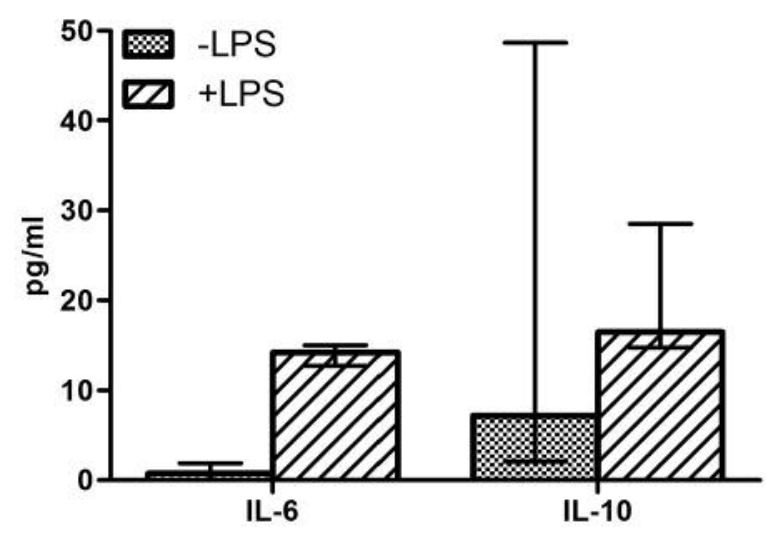

B

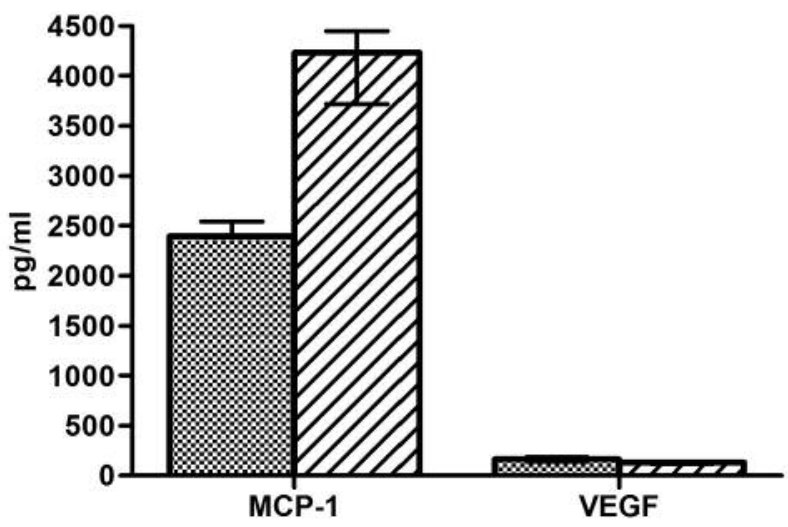

Figure 4. Functional toll-like recptor 4 (TLR4) screening. Supernatants of ID8-fLuc cells $\left(5 \times 10^{5}\right)$ treated with(out) lipopolysaccharide (LPS) $(10 \mu \mathrm{g} / \mathrm{ml})$ were analyzed for the presence of soluble mediators using cytometric bead array $(C B A)$ and enzyme-linked immunosorbent assay (ELISA). No statistically significant differences were found by the Mann-Whitney test $(p>0.05)$. IL: Interleukin, MCP-1: monocyte chemoattractant protein-1,VEGF: vascular endothelial growth factor.

untreated mice (Figure 7C). In contrast, the level of $\mathrm{CD} 45^{+} \mathrm{CD} 11 \mathrm{~b}^{+} \mathrm{GR} 1^{+}$granulocytes was clearly be reduced by the combination immunotherapy, compared to tumorbearing controls (Figure 7D). The proportion of NK cells was low in the ascites of all mice (Figure 7E).

To evaluate the immune response, we measured IL-12p70 and IL-6 levels in the ascites of the mice. Both cytokines increased after three combination immunotherapy vaccines. However, we also observed a rise in the concentrations of IL-10, MCP-1 and VEGF (Figure 8). CBA analysis demonstrated that the concentrations of IL-1 $\beta$, IL-17A, TNF$\alpha$ and IFN- $\gamma$ in murine ascites were extremely low or undetectable. Therefore, these values were not considered for interpretation.

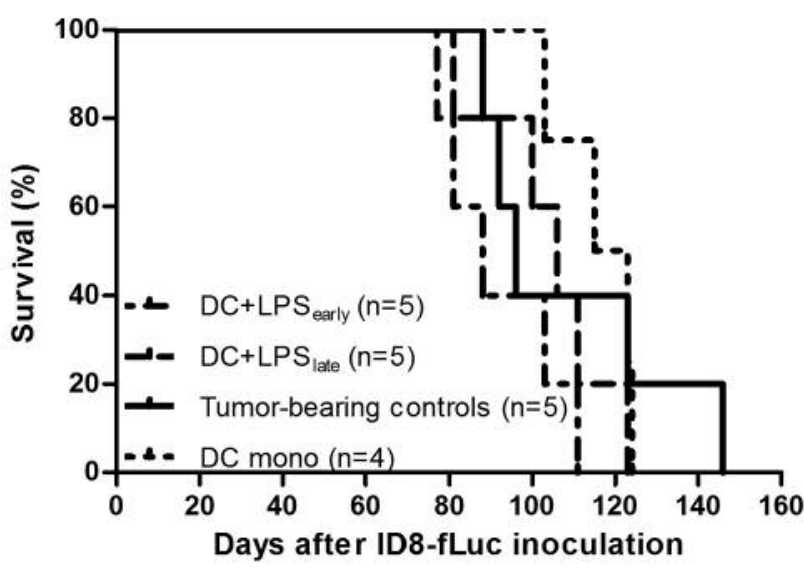

Figure 5. Dendritic cell (DC) immunotherapy in combination with tolllike recptor 4 (TLR4) agonist administration. DC-based vaccination was administered subcutaneously to the corresponding groups for 3 consecutive weeks starting on day 21 after ID8-fLuc inoculation. Lipopolysaccharide (LPS) was injected i.p. in correspondence to a fixed schedule: early administration $\left(D C+L P S_{\text {early }}\right)$ occurred on day 7,14 and 21 after ID8-fLuc inoculation; late administration (DC+LPS late) occurred on days 20, 27 and 34 after ID8-fLuc inoculation. A Kaplan-Meier plot was used to evaluate the effect of the combination immunotherapy in terms of survival. Median survival: 88 days for $D C+L P S_{\text {early }}, 106$ days for $D C+L P S_{\text {late }}, 96$ days for tumor-bearing controls and 119 days for DC monotherapy-treated mice. Mice of the DC+LPS early group had a significantly shorter median survival compared to mice which only received DC immunotherapy (DC mono) $(p=0.0218)$.

\section{Discussion}

To overcome immunosuppression in ovarian cancer, we combined DCs loaded with Hyp-PDT-treated lysate with a TLR4 agonist administrated to the TME. Recent literature underlines the tumor-suppressive features of TLR agonists $(18,20,22,23,30)$. TLR activation in immune cells within the TME may shift the immunosuppressive profile towards an immunostimulatory one. Unfortunately, mice treated with the combination regimen, in which the TLR4 agonist LPS was given one day prior to each DC immunotherapy, showed no significant survival benefit compared to mice treated with DC mono-treated mice or untreated controls.

Reviewing the literature, several research teams report that the administration of a TLR agonist into the TME is like handling a double-edged sword. TLR may not only induce an antitumoral immune response, but also cause tumor progression by stimulation of TLR present on the cancer cells $(7,26,31-33)$. We demonstrated that TLR4 was indeed expressed in the ID8-fLuc cell line. However, we did not observe a significant LPS-induced increase in ID8-fLuc cell proliferation and functional analysis of TLR4 revealed no significant difference in downstream production of 


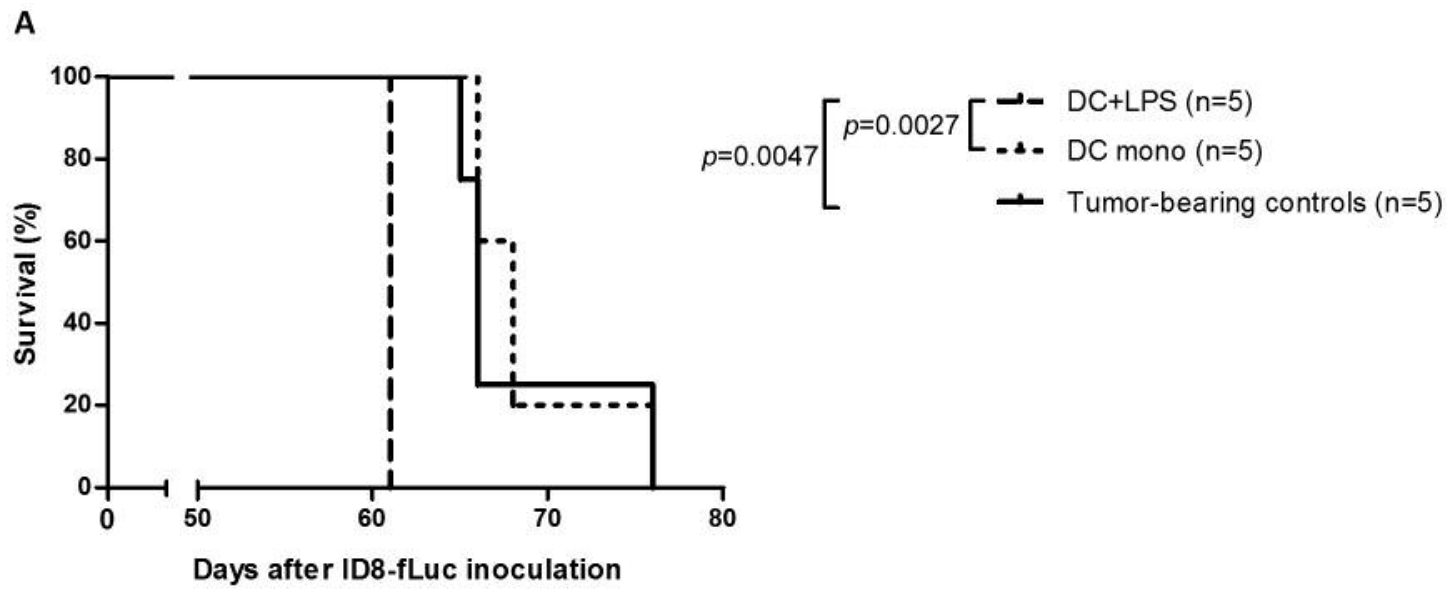

B

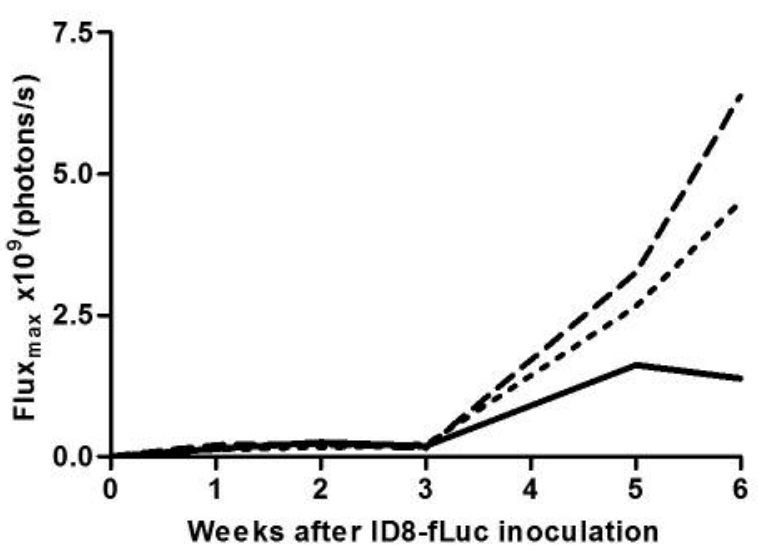

C

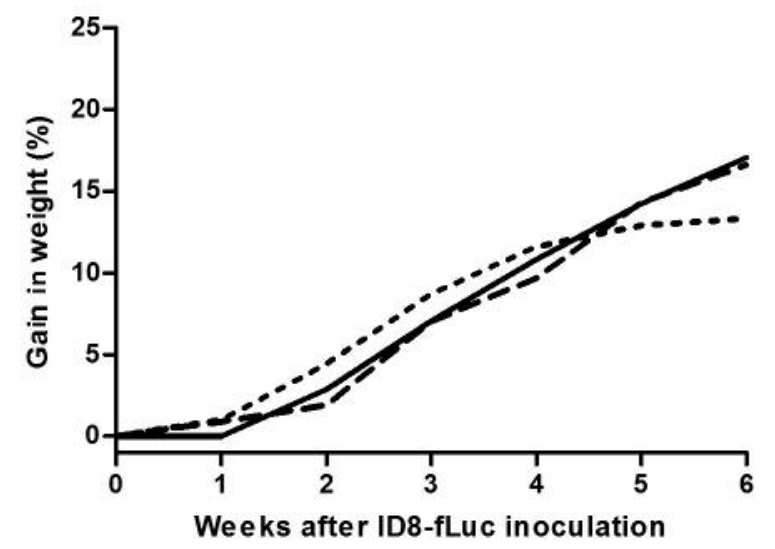

Figure 6. Administration of a toll-like recptor 4 (TLR4) agonist one day prior to each dendritic cell (DC) immunotherapy. Female ID8-fLuc tumorbearing C57BL/6 mice were treated with lipopolysaccharide (LPS) on days 20, 27 and 34 after ID8-fLuc inoculation, mature DC were administered on days 21, 28 and 35. A: A Kaplan-Meier plot was used to assess the effect of the combination immunotherapy in terms of survival. Median survival: 61 days for DC + lipopolysaccharide (LPS), 66 days for DC mono and 68 days for tumor-bearing controls. All mice of the DC+LPS group had a poor clinical appearance and a significantly shorter median survival compared to the other groups by log-rank test. B: The tumor load was non-invasively monitored by bioluminescence imaging (BLI) performed on weekly basis starting 1 week after ID8-fLuc inoculation. The change in median bioluminescent signal intensity up to 6 weeks after ID8-fLuc inoculation is shown. No statistically significant differences were found by Kruskal-Wallis test. C:Ascites development was monitored by weight measurements performed at least three times a week. Change in median weight up to 6 weeks after ID8-fLuc inoculation is shown. No statistically significant differences were found by the Kruskal-Wallis test. One of the untreated control mice unexpectedly died 37 days after ID8-fLuc inoculation. Therefore, this mouse was excluded from statistical analyses.

immunosuppressive molecules (IL-6, IL-10, MCP-1 and VEGF) between LPS-treated and untreated ID8-fLuc cells. Furthermore, the sole use of LPS did not alter the immunohistochemical expression of TLR4 in tumor cells. Therefore, the presence of TLR4 in ovarian cancer tissue does not correlate with the lack of therapeutic advantage when using combination immunotherapy. It might be that the timing and dosage of LPS administration was still not optimal. Paulos et al. administered LPS one day after adoptive $T$ cell therapy in an irradiated mouse model of melanoma and noted significantly enhanced tumor destruction (34). New experiments should be performed to further evaluate dose-response and timing of TLR4 administration.

We hypothesize that a positive immune reaction induced by the combination immunotherapy was abolished by the immunosuppressive TME. Indeed, our results show a positive intratumoral immune effect of the vaccine [decrease in $\mathrm{T}_{\text {reg }}$ and increase in NK cells, in accordance with D'Agostini et al. (35)], but a lack of it within the tumor environment (ascites) (low concentrations of IL-1 $\beta$, IL-17A and IFN- $\gamma$ and high concentrations of IL-6, IL-10, MCP-1 
A

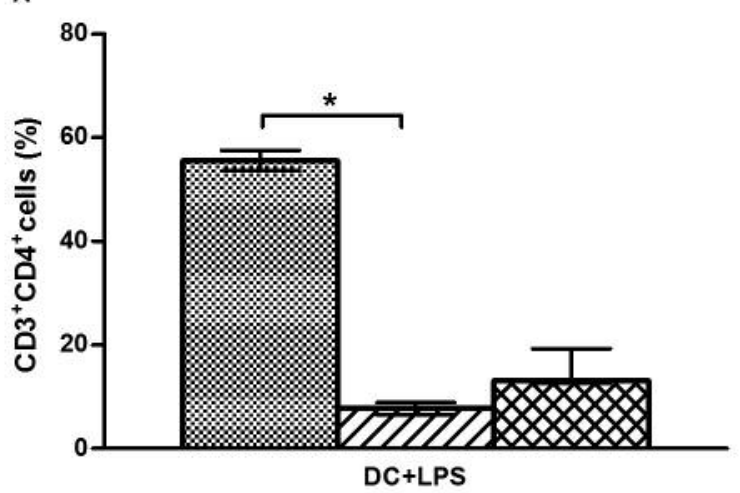

C

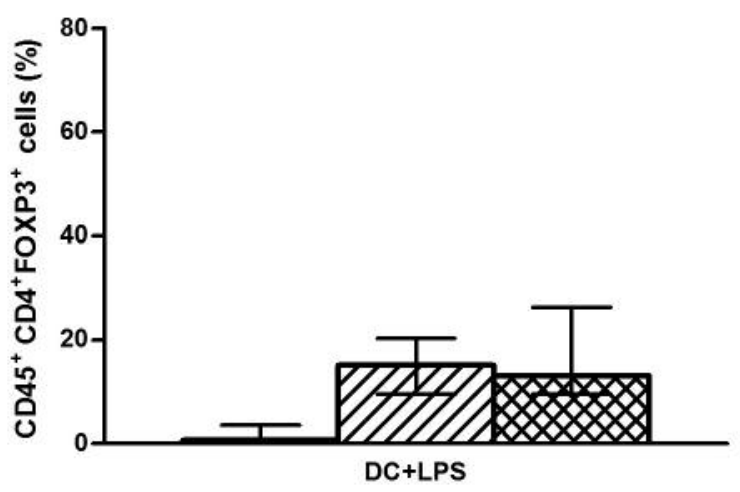

E

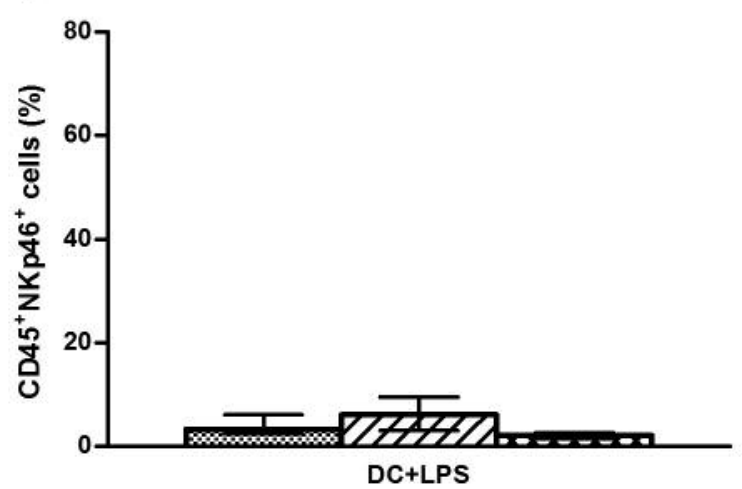

B

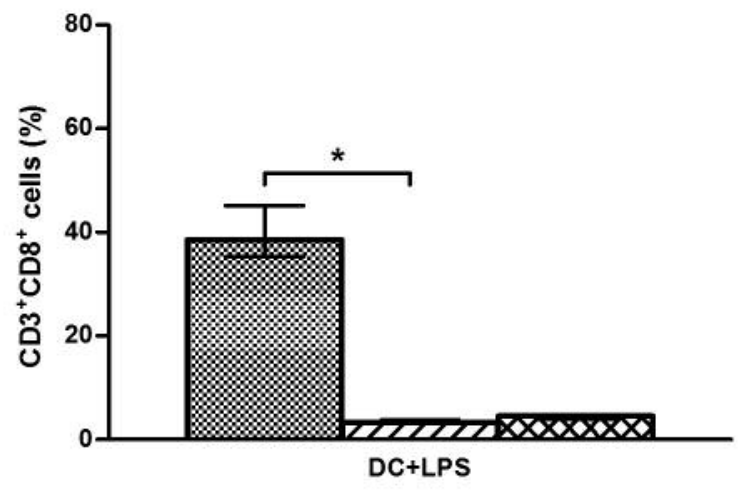

D

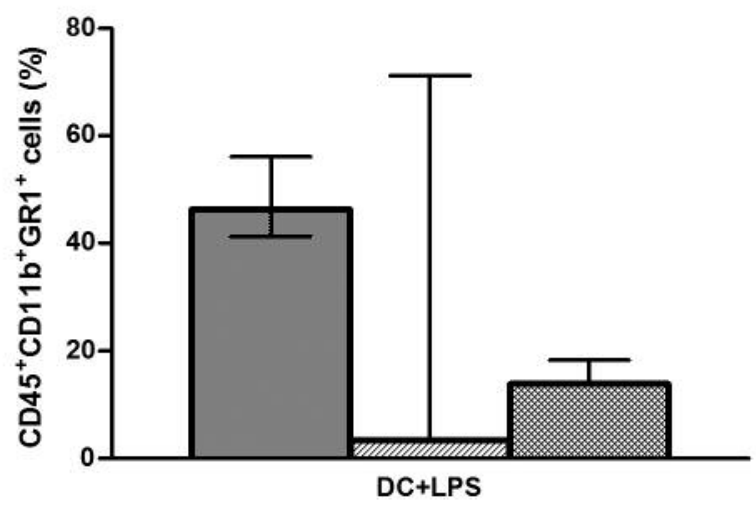

Figure 7. Changes in immune cells present in murine ascites during combination immunotherapy. Dendritic cell (DC) immunotherapy in combination with lipopolysaccharide (LPS) was administered one day prior to each DC-based vaccination, i.e. on days 20, 27 and 34 after ID8-fLuc inoculation. To evaluate changes in soluble mediators, murine ascites was collected at three different time points for immune monitoring: before, after two and three vaccinations, corresponding to 21,35 and 42 days after ID8-fLuc inoculation. Fluorescence-activated cell sorting (FACS) analysis revealed the relative number of cluster of differentiation $3(\mathrm{CD} 3)^{+} \mathrm{CD} 4^{+}$T-lymphocytes $(\mathrm{A}), \mathrm{CD} 3^{+} \mathrm{CD} 8^{+}$T-lymphocytes $(\mathrm{B}), \mathrm{CD} 45^{+} \mathrm{CD} 4^{+}$forkhead box $\mathrm{P3}(\mathrm{FOXP3})^{+}$ regulatory T-cells $\left(T_{\text {reg }}\right)(C), C D 45^{+} C D 11 b^{+}$granulocytic marker $\left(\right.$Ly-6G/Ly-6C/GRI $\left.{ }^{+}\right)$granulocytes $(D)$ and $C D 45^{+} C D 335(N K p 46)^{+}$natural killer $(N K)$ cells $(E)$ in ascites of mice following combination immunotherapy. Statistically significant difference by Kruskal-Wallis test at *p<0.05.

and VEGF in the ascites of treated mice). Moreover, the number of $\mathrm{CD}^{+}{ }^{+} \mathrm{CD} 4^{+}$and $\mathrm{CD} 3{ }^{+} \mathrm{CD} 8^{+} \mathrm{T}$-cells in ascites significantly decreased $(p<0.05)$ after two vaccinations compared to tumor-bearing controls and simultaneously the proportion of $\mathrm{T}_{\text {reg }}$ had increased. In contrast, the combination immunotherapy seemed to lower the proportion of granulocytes, with possible (but unconfirmed) MDSC potential. 
A

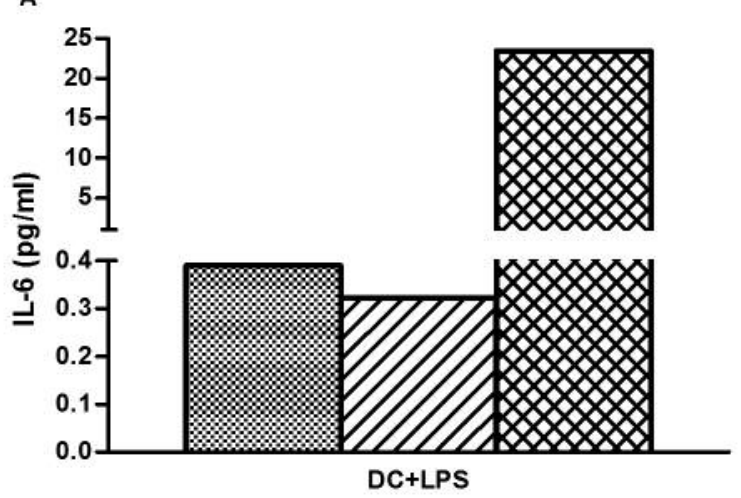

C

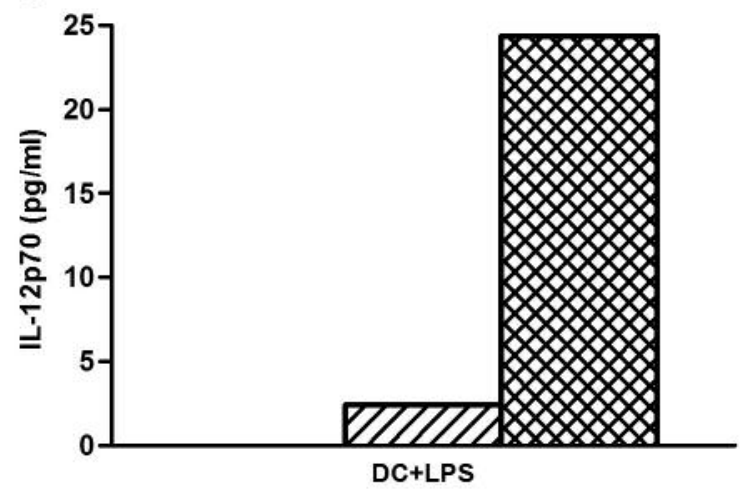

E

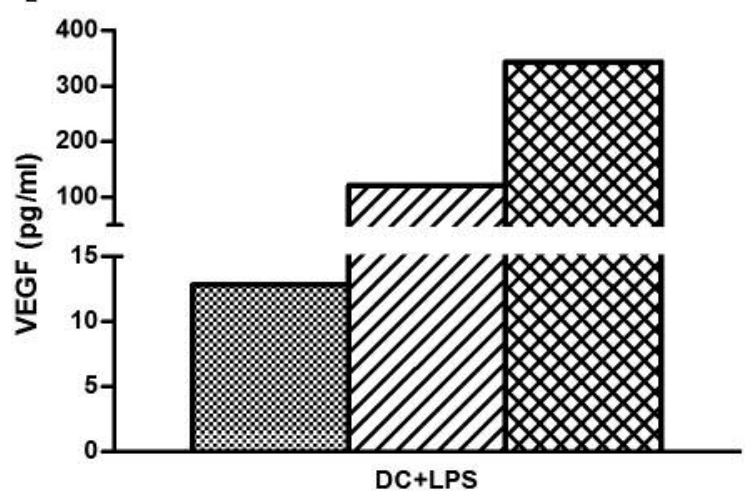

B

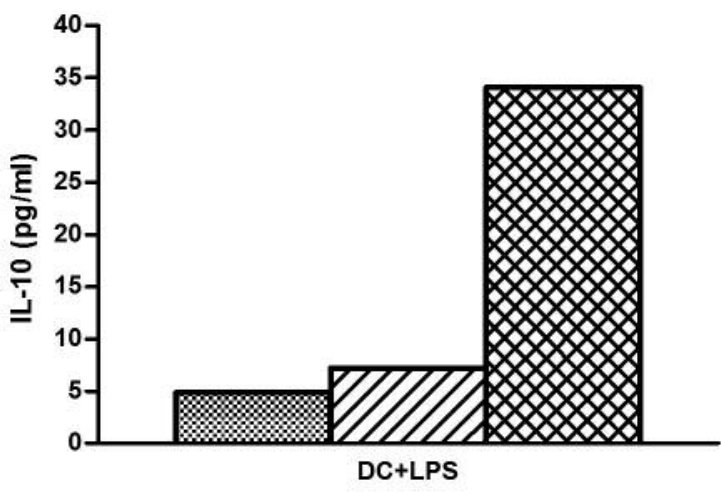

D

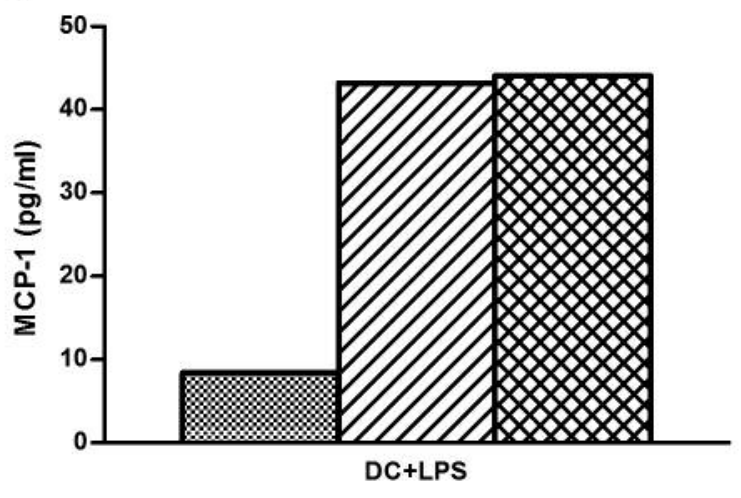

Before DC-based vaccination
After 2 DC-based vaccinations

After 3 DC-based vaccinations

Figure 8. Changes in soluble mediators present in murine ascites during combination immunotherapy with dendritic cells (DC) and lipopolysaccharide (LPS). DC immunotherapy in combination with LPS was administered one day prior to each DC-based vaccination, i.e. on days 20,27 and 34 after ID8-fLuc inoculation. To evaluate changes in soluble mediators, murine ascites was collected at three different time points for immune monitoring: before, after two and three vaccinations, corresponding to 21, 35 and 42 days after ID8-fLuc inoculation. Cytometric bead array (CBA) and enzymelinked immunosorbent assay (ELISA) analysis revealed the concentration of Interleukin-6 (IL-6) (A), IL-10 (B), IL-12p70 (C), monocyte chemoattractant protein-1 (MCP-1) (D) and vascular endothelial growth factor (VEGF) (E) in ascites of mice following combination immunotherapy.

Immune analysis revealed high levels of IL-6, IL-10, MCP1 and VEGF in the ascites of all mice. Several research groups reported that high levels of these mediators in ascites can be associated with ovarian cancer progression and poor prognosis
(5, 36-42). Furthermore, we observed an upward trend in expression of MCP-1, a well-studied chemokine, which could partially explain the influx of immuno-suppressive cells such as MDSCs, TAMs and $\mathrm{T}_{\text {reg }}$ into the tumor environment 
(ascites). According to Takaishi et al., the presence of activated TAMs is associated with high levels of IL-6 and IL-10 in ascites of patients with ovarian cancer (43). Therefore, we could speculate that high levels of IL-6 and IL-10 may have been indicative of the infiltration of TAMs into the TME. FACS analysis confirmed an increase in $\mathrm{CD}^{+}{ }^{+} \mathrm{FOXP} 3^{+} \mathrm{T}_{\text {reg }}$ in the ascites of treated mice. It is well known that the accumulation of $\mathrm{T}_{\text {reg }}$ in the TME results in T-cell anergy and apoptosis $(8,44)$. Furthermore, Curiel et al. observed that a low ratio of $\mathrm{CD}^{+}$T-cells and $\mathrm{CD} 4{ }^{+} \mathrm{CD} 25^{+} \mathrm{FOXP} 3^{+} \mathrm{T}_{\text {reg }}$ is associated with a poor outcome in patients with ovarian cancer (44). Additionally, we found an abundance of VEGF in the ascites of treated mice. Together with MCP-1, VEGF contributes to the recruitment of MDSCs into the TME (8). Although immune analysis showed an upward trend in MCP1 and VEGF expression, we detected only a low level of GR $1^{+}$ myeloid cells in murine ascites. In addition to Treg and TAMs, MDSCs can also play a key role in immunosuppression (8).

To conclude, the administration of optimized DC-based vaccines, used as monotherapy or in combination with the TLR4 agonist LPS, was unable to generate a significant survival benefit in an ID8-fLuc mouse model of ovarian cancer. Although immune analysis revealed a positive intratumoral immune effect, we consider the immunosuppressive signature of the TME as a plausible cause of therapy failure. Future immunotherapeutic developments should, therefore, focus on how to control immunosuppression in ovarian cancer.

\section{Acknowledgements}

The Authors would like to thank the Olivia Hendrickx Research Fund for their support. A. Coosemans, A.D. Garg and G. Vande Velde are supported by the Fund for Scientific Research Flanders (FWO).

\section{References}

1 Ferlay J, Steliarova-Foucher E, Lortet-Tieulent J and Rosso S: Cancer incidence and mortality patterns in Europe: Estimates for 40 countries in 2012. Eur J Cancer 49: 1374-1403, 2013.

2 American Cancer Society. Cancer Facts \& Figures 2013. Am Cancer Soc, Atlanta, GA, USA, 2013.

3 Kandukuri SR and Rao J: FIGO 2013 staging system for ovarian cancer: what is new in comparison to the 1988 staging system? Curr Opin Obstet Gynecol 27: 48-52, 2015.

4 Vergote I, Tropé CG, Amant F, Kristensen GB, Ehlen T, Johnson $\mathrm{N}$, Verheijen RHM, van der Burg MEL, Lacave AJ, Panici PB Kenter GG, Casado A, Mendiola C, Coens C, Verleye L, Stuart GCE, Pecorelli S and Reed NS: Neoadjuvant chemotherapy or primary surgery in advanced ovarian cancer. N Engl J Med 363(10): 943-953, 2010.

5 Hanahan D and Weinberg RA: Hallmarks of cancer: the next generation. Cell 144: 646-674, 2011.

6 Coosemans A, Decoene J, Baert T, Laenen A, Verschuere T, Seys $\mathrm{S}$ and Vergote I: Immunosuppressive parameters in serum of ovarian cancer patients change during the disease course. Oncoimmunology 5(4): e1111505, 2016.

7 Schreiber RD, Old LJ and Smyth MJ: Cancer immunoediting: integrating immunity's roles in cancer suppression and promotion. Science 331: 1565-1570, 2011.

8 Baert $\mathrm{T}$, Timmerman $\mathrm{D}$, Vergote $\mathrm{I}$ and Coosemans A: Immunological parameters as a new lead in the diagnosis of ovarian cancer. Facts Views Vis Obgyn 1: 67-72, 2015.

9 Leffers N, Daemen T, Helfrich W, Boezen HM, Cohlen BJ, Melief CJ and Nijman HW: Antigen-specific active immunotherapy for ovarian cancer. Cochrane Database Syst Rev 9: CD007287, 2014.

10 Coosemans A, Baert T and Vergote I: A view on dendritic cell immunotherapy in ovarian cancer: how far have we come? Facts Views Vis Obgyn 7(1): 73-78, 2015.

11 Melero I, Berman DM, Aznar MA, Korman AJ, Pérez Garcia JL and Haanen J: Evolving synergistic combinations of targeted immunotherapies to combat cancer. Nat Rev Cancer 15: 457$472,2015$.

12 Rivera LB and Bergers G: Intertwined regulation of angiogenesis and immunity by myeloid cells. Trends Immunol 36: 240-249, 2015.

13 Garg AD, Galluzzi L, Apetoh L, Baert T, Birge RB, Bravo-San Pedro JM, Breckpot K, Brough D, Chaurio R, Cirone M, Coosemans A, Coulie PG, De Ruysscher D, Dini L, de Witte P, Dudek-Peric AM, Faggioni A, Fucikova J, Gaipl US, Golab J, Gougeon ML, Hamblin MR, Hemminki A, Herrmann M, Hodge JW, Kepp O, Kroemer G, Krysko DV, Land WG, Madeo F, Manfredi AA, Mattarollo SR, Maueroder C, Merendino N, Multhoff G, Pabst T, Ricci JE, Riganti C, Romano E, Rufo N, Smyth MJ, Sonnemann J, Spisek R, Stagg J, Vacchelli E, Vandenabeele P, Vandenberk L, Van den Eynde BJ, Van Gool S, Velotti F, Zitvogel L and Agostinis P: Molecular and translational classifications of DAMPs in immunogenic cell death. Front Immunol 6: 588, 2015.

14 Vacchelli E, Eggermont A, Sautès-Fridman C, Galon J, Zitvogel L, Kroemer G and Galluzzi L: Trial Watch: Toll-like receptor agonists for cancer therapy. Oncoimmunology 2(8): e25238, 2013.

15 Bhardwaj N, Gnjatic S and Sawhney N: TLR agonists: Are they good adjuvants? Cancer J 16(4): 382-391, 2010.

16 Newton K and Dixit VM: Signaling in innate immunity and inflammation. Cold Spring Harb Perspect Biol 4: pii: a006049, 2012.

17 Garg AD, Vandenberk L, Koks C, Verschuere T, Boon L, Van Gool SW and Agostinis P: Dendritic cell vaccines based on immunogenic cell death elicit danger signals and T-cell-driven rejection of high-grade glioma. Sci Transl Med 8: 328ra327, 2016.

18 Muccioli $\mathrm{M}$ and Benencia F: Toll-like receptors in ovarian cancer as targets for immunotherapies. Front Immunol 5: 341, 2014.

19 Engel AL, Holt GE and Hailing L: The pharmacokinetics of Toll-like receptor agonists and the impact on the immune system. Expert Rev Clin Pharmacol 4(2): 275-289, 2012.

20 Mariani CL, Rajon D, Bova FJ and Streit WJ: Nonspecific immunotherapy with intratumoral lipopolysaccharide and zymosan A but not GM-CSF leads to an effective anti-tumor response in subcutaneous RG-2 gliomas. J Neurooncol 85: 231$240,2007$. 
21 Currie AJ, van der Most RG, Broomfield SA, Prosser AC, Tovey MG and Robinson BWS: Targeting the effector site with IFN$\alpha \beta$-inducing TLR ligands reactivates tumor-resident CD8 T-cell responses to eradicate established solid tumors. J Immunol 180(3): 1535-1544, 2008.

22 Vogel SN, Hilfiker ML and Caufield MJ: Endotoxin-induced T lymphocyte proliferation. J Immunol 130(4): 1774-1779, 1983.

23 Scarlett UK, Rutkowski MR, Rauwerdink AM, Fields J, Escovar-Fadul X, Baird J, Cubillos-Ruiz JR, Jacobs AC, Gonzalez JL, Weaver J, Fiering S and Conejo-Garcia JR: Ovarian cancer progression is controlled by phenotypic changes in dendritic cells. J Exp Med 209(3): 495-506, 2012.

24 Brueseke TJ and Tewari KS: Toll-like receptor 8: Augmentation of innate immunity in platinum-resistant ovarian carcinoma. Clin Pharmacol Adv Appl 5(1): 13-19, 2013.

25 Huang B, Zhao J, Unkeless JC, Feng ZH and Xiong H: TLR signaling by tumor and immune cells: a double-edged sword. Oncogene 27: 218-224, 2008.

26 Zhou M, McFarland-Mancini MM, Funk HM, Husseinzadeh N, Mounajjed T and Drew AF: Toll-like receptor expression in normal ovary and ovarian tumors. Cancer Immunol Immunother 58: 1375-1385, 2009.

27 Baert T, Verschuere T, Van Hoylandt A, Gijsbers R, Vergote I and Coosemans A: The dark side of ID8-Luc2: pitfalls for luciferase-tagged murine models for ovarian cancer. J Immunother Cancer 3: 57, 2015.

28 Guillen, J: FELASA guidelines and recommendations. J Am Assoc Lab Anim Sci 51: 311-321, 2012.

29 Baert T, Garg A, Vindevogel E, Van Hoylandt A, Agostinis P, Vergote I and Coosemans A: In vitro generation of murine dendritic cells: optimizing the culturing protocol. Anticancer Res 36(11): xxxx-Xxxx, 2016.

30 Bellora F, Castriconi R, Dondero A, Pessino A, Nencioni A, Liggieri G, Moretta L, Mantovani A, Moretta A and Bottino C: TLR activation of tumor-associated macrophages from ovarian cancer patients triggers cytolytic activity of NK cells. Eur J Immunol 44: 1814-1822, 2014.

31 Kelly MG, Alvero AB, Chen R, Silasi DA, Abrahams VM, Chan S, Visintin I, Rutherford T and Mor G: TLR-4 signaling promotes tumor growth and paclitaxel chemoresistance in ovarian cancer. Cancer Res 66(7): 3859-3868, 2006.

32 Chen R, Alvero AB, Silasi D, Steffensen KD and Mor G: Cancers take their Toll - the function and regulation of Toll-like receptors in cancer cells. Oncogene 27: 225-233, 2008.

$33 \mathrm{Kim}$ KH, Jo MS, Suh DS, Yoon MS, Shin DH, Lee JH and Choi $\mathrm{KU}$ : Expression and significance of the TLR4/MyD88 signaling pathway in ovarian epithelial cancers. World J Surg Oncol 10: 193, 2012.

34 Paulos CM, Wrzesinski C, Kaiser A, Hinrichs CS, Chieppa M, Cassard M, Palmer DC, Boni A, Muranski P, Yu Z, Gattinoni L, Antony PA, Rosenberg SA and Restifo NP: Microbial translocation augments the function of adoptively transferred self/tumor-specific CD8+ T-cells via TLR4 signaling. J Clin Invest 117: 2197-2204, 2007.
35 D’Agostini C, Pica F, Febbraro G, Grelli S, Chiavaroli C and Garaci E: Antitumour effect of OM-174 and cyclophosphamide on murine B16 melanoma in different experimental conditions. Int Immunopharmacol 5: 1205-1212, 2005.

36 Hata K, Watanabe $\mathrm{Y}$, Nakai $\mathrm{H}$, Hata $\mathrm{T}$ and Hoshiai $\mathrm{H}$ : Expression of the Vascular endothelial growth factor (VEGF) gene in epithelial ovarian cancer: An approach to anti-VEGF therapy. Anticancer Res 31: 731-738, 2011.

37 Coward J, Kulbe H, Chakravarty P, Leader D, Vassileva V, Leinster DA, Thompson R, Schioppa T, Nemeth J, Vermeulen J, Singh N, Avril N, Cummings J, Rexhepaj E, Jirström K, Gallagher WM, Brennan DJ, McNeish LA and Balkwill FR: Interleukin-6 as a therapeutic target in human ovarian cancer. Clin Cancer Res 17(18): 6083-6096, 2011.

38 Guo Y, Nemeth J, O'Brien C, Susa M, Liu X, Zhang Z, Choy E, Mankin H, Hornicek F and Duan Z: Effects of siltuximab on the IL-6-induced signaling pathway in ovarian cancer. Clin Cancer Res 16(23): 5759-5769, 2010.

39 Said N, Socha MJ, Olearczyk JJ, Elmarakby AA, Imig JD and Motamed K: Normalization of the ovarian cancer microenvironment by SPARC. Mol cancer Res 5(10): 1015-1030, 2007.

40 Ahmed N and Stenvers KL: Getting to know ovarian cancer ascites: opportunities for targeted therapy-based translational research. Front Oncol 3: 256, 2013.

41 Fisher DT, Appenheimer MM and Evans SS: The two faces of IL-6 in the tumor microenvironment. Semin Immunol 26(1): 3847, 2014.

42 Hart KM, Byrne KT, Molloy MJ, Usherwood EM and Berwin B: IL-10 immunomodulation of myeloid cells regulates a murine model of ovarian cancer. Front Immunol 2: 29, 2011.

43 Takaishi K, Komohara Y, Tashiro H, Ohtake H, Nakagawa T, Katabuchi $\mathrm{H}$ and Takeyaet M: Involvement of M2-polarized macrophages in the ascites from advanced epithelial ovarian carcinoma in tumor progression via STAT3 activation. Cancer Sci 101(10): 2128-2136, 2010.

44 Curiel TJ, Coukos G, Zou L, Alvarez X, Cheng P, Mottram P, Evdemon-Hogan M, Conejo-Garcia JR, Zhang L, Burow M, Zhu Y, Wei S, Kryczek I, Daniel B, Gordon A, Myers L, Lackner A, Disis AL, Knutson KL, Chen L and Zou W: Specific recruitment of regulatory T-cells in ovarian carcinoma fosters immune privilege and predicts reduced survival. Nat Med 10(9): 942-949, 2004.
Received August 22, 2016

Revised September 21, 2016

Accepted September 22, 2016 